\title{
Hypernatraemic dehydration: Do we have consensus on its treatment?
}

Hypernatraemia occurs in some $10-20 \%$ of children with dehydrating gastroenteritis, and is more common in infants $>6$ months of age. Of concern is the fact that hypernatraemia - rather than iso- or hyponatraemic dehydration - is associated with high mortality and morbidity rates. In this issue of $S A J C H$, Hariram et al. ${ }^{[1]}$ report on the presentation of hypernatraemic dehydration among admitted infants and young children with acute gastroenteritis at King Edward VIII Hospital in Durban. They found a prevalence of just over $12 \%$, using a serum Na level of $\geq 150 \mathrm{mmol} / \mathrm{L}$ as the defining characteristic. There is no universally accepted definition of hypernatraemia, and a number of researchers have used a lower $\mathrm{Na}$ threshold (>145 mmol/L) to define hypernatraemia. The prevalence among children admitted with dehydrating gastroenteritis in Durban is similar to the $16 \%$ reported in a convenience sample (aged $<64$ months) in Stellenbosch that used $145 \mathrm{mmol} / \mathrm{L}$ as the cut-off, ${ }^{[2]}$ but is much lower than the $41 \%$ reported in another convenience sample (aged $<2$ years) in Johannesburg, also using the latter cut-off. ${ }^{[3]}$ The higher incidence in the Johannesburg study might reflect the younger age of the sample studied. Despite the relatively common occurrence of hypernatraemia in acute dehydrating gastroenteritis, there is no consensus on how these children should be treated to reduce the risk of long-term sequelae. In the Durban cohort, $>60 \%$ of children had neurological abnormalities during hospitalisation, but it is unclear if these neurological sequelae persisted following discharge.

Worldwide, there are no randomised controlled trials that have assessed the rate at which hypernatraemia should be corrected, or how this should be achieved. In a retrospective analysis of 62 patients with hypernatraemia $(>155 \mathrm{mmol} / \mathrm{L})$ in Israel, the researchers concluded that serum $\mathrm{Na}$ levels could be safely reduced by $0.65 \mathrm{mmol} / \mathrm{L} / \mathrm{h}{ }^{[4]}$ In the Durban study, the serum $\mathrm{Na}$ fell at a rate of between 0.5 and $1.0 \mathrm{mmol} / \mathrm{L}$, with no evidence that the complication rate was any higher in those with higher rather than lower rates of fall. These figures are slightly higher than the rate of fall $(<0.5 \mathrm{mmol} / \mathrm{L} / \mathrm{h})$ that has been recommended by the majority of researchers in the field. There is general agreement that shocked and dehydrated infants should be treated initially with rapid intravenous boluses of isotonic saline at a rate of $20 \mathrm{~mL} / \mathrm{kg}$ of body weight, although there is concern about this recommendation following the Fluid Expansion as Supportive Therapy (FEAST) trial, which studied the use of bolus intravenous (IV) infusions in children with severe infection and impaired perfusion. ${ }^{[5]}$ In this large trial, the mortality was higher in those children assigned to an IV bolus than those receiving continuous maintenance fluid. It should be pointed out, however, that children with acute gastroenteritis were specifically excluded from the trial, and so the relevance of the finding to this discussion is unknown.

Once adequate perfusion is achieved, there appears to be consensus that complete rehydration should take place slowly, at least over 48 to 72 hours. Furthermore, IV fluids should only be used when rehydration and fluid maintenance cannot be achieved orally. The most important aspect of slow rehydration is to ensure that the fall in serum $\mathrm{Na}$ is gradual; with frequent monitoring of the $\mathrm{Na}$ level, clinicians can further adjust the rate of replacement fluid to prevent a too-rapid fall in $\mathrm{Na}$ levels. To calculate the fluid requirement over this period, the free water deficit needs to be determined over and above the fluid requirements for maintenance and ongoing losses. ${ }^{[6]}$ It is recommended that isotonic saline with $5 \%$ dextrose should be used routinely, ${ }^{[6]}$ although regular monitoring of the hydration state and $\mathrm{Na}$ levels is required so that the volume and $\mathrm{Na}$ content of the infusate fluid can be adjusted as needed. Some centres recommend tailoring the fluid composition to the individual needs of the child (see the Durban protocol ${ }^{[1]}$ and Schwaderer and Schwartz ${ }^{[8]}$ ). A recent systematic review of dysnatraemias in acute gastroenteritis has confirmed that the risk of developing hyponatraemia during the management of children with dehydrating gastroenteritis is greater if hypotonic saline solutions are used. ${ }^{[7]}$

In conclusion, there is an urgent need for randomised controlled trials to be instituted, similar to the FEAST study but aimed at addressing the management of hypernatraemic dehydration in children with acute gastroenteritis. It is possible that, as was the case following the FEAST study, management may be turned on its head.

1. Hariram T, Naidoo K, Ramji S. Hypernatraemic dehydration in infants with acute gastroenteritis at King Edward VIII Hospital. S Afr J Child Health 2018;12(1):10-14. https://doi.org/10.7196/SAJCH.2018.v12i1.1424

2. Cooke ML, Nel ED, Cotton MF. Pre-hospital management and risk factors in children with acute diarrhoea admitted to a short-stay ward in an urban South African hospital with a high HIV burden. S Afr J Child Health 2013;7(3):84-87. https://doi.org/10.7196/SAJCH.2013.v7i3.472

3. Hoosain SBG. Hypernatraemic dehydration in acute gastroenteritis - a descriptive audit of prehospital management and predisposing factors. wiredspace.wits.ac.za/jspu/bitstream/10539/23167/1/Research\%20report\%20 final.pdf (accessed 9 April 2018).

4. Ben-Shalom E, Toker O, Schwartz S. Hypernatremic dehydration in young children: Is there a solution? IMAJ 2016;18:95-99.

5. Maitland K, Kiguli S, Opaka RO, et al. Mortality after fluid bolus in African children with severe infection. N Engl J Med 2011;364:2483-2495. https://doi. org/10.1056/NEJMoa1101549

6. Anigilaje EA. Management of diarrhoeal dehydration in childhood: A review for clinicians in developing countries. Front Pediatr 2018;6:28. https://doi. org/10.3389/fped.2018.00028

7. Grisaru S, Xie J, Samuel S, Freedman SB. Iatrogenic dysnatremia in children with acute gastroenteritis in high-income countries: A systematic review. Front Pediatr 2017;5:210. https://doi.org/10.3389/fped.2017.00210

8. Schwaderer AL, Schwartz GW. Treating hypernatremic dehydration. Pediatr Rev 2005; 26:148 https://doi.org/10.1542/pir.26-4-148

S Afr J Child Health 2018;12(1):2. DOI:10.7196/SAJCH.2018.v12i1.1554

\section{John M Pettifor}

Editor, South African Journal of Child Health

Department of Paediatrics, University of the Witwatersrand,

Johannesburg, South Africa

john.pettifor@wits.ac.za

\section{Sanjay G Lala}

Department of Paediatrics, University of the Witwatersrand and Chris Hani Baragwanath Academic Hospital, Johannesburg, South Africa

sanjay.lala@wits.ac.za 